\title{
A ALTERIDADE COMO PERFIL ÉTICO E SOLIDÁRIO DO PROFESSOR AO SE COLOCAR NA POSIÇÃO "DO OUTRO"
}

\author{
THE OTHERNESS AS ETHICAL AND SUPPORTIVE TEACHER PROFILE WHEN \\ PUT TO "THE OTHER"
}

\author{
${ }^{1}$ Aline Cristina Alves \\ ${ }^{2}$ Roseli Borin
}

\section{RESUMO}

Hodiernamente as preocupações se voltam para alteridade no seio das sociedades. Direitos fundamentais foram reconhecidos e garantidos a todos os cidadãos brasileiros, como o da igualdade. Mesmo tendo-se esses direitos assegurados não se dá o devido conhecimento desses institutos de modo crítico, um papel que deve, mormente, ser assumido pelo professor

/educador. Acredita-se que cabe ao professor infundir este perfil ético e crítico na busca de transformações no sistema para a implementação do autentico Estado Democrático de Direito no Brasil.

Palavras-chave: Alteridade, Dignidade humana, Papel do professor

\begin{abstract}
Today the concerns turn to otherness within societies. Fundamental rights were recognized and guaranteed to all Brazilian citizens, such as the equality. Even with these rights provided it be not given critically the due knowledge of these institutes, a role that should, mainly, and a part that should be taken over by professor/educator. It is believed that it is up to the teacher to infuse this ethical and critical profile in search of transformations in the system for the implementation of authentic Democratic State of Law in Brazil.
\end{abstract}

Keywords: Otherness, Human dignity, Role of the teacher

\footnotetext{
${ }^{1}$ Doutorando em Ciências Jurídicas e Políticas na Universidad Pablo de Olavide, UPO, Espanha. Coordenadora do curso de Direito da Faculdade Projeção - FAPRO, Brasília - DF (Brasil). E-mail: nina.alves@gmail.com

${ }^{2}$ Doutora em Sistema Constitucional de Garantia de Direitos Instituto Toledo de Ensino - ITE, São Paulo (Brasil). Professora da Faculdade Metropolitana de MARINGÁ, UNIFAMMA, Paraná (Brasil).

E-mail: roseborin@hotmail.com
} 


\section{INTRODUÇÃO}

O Estado-constitucional brasileiro contemporâneo possui como meta integradora o princípio da dignidade da pessoa humana para a inclusão de todos.

Assim, o objetivo deste artigo é promover uma reflexão acerca da capacidade e poder que o professor tem de transformar o sistema ao atuar na formação de pessoas incutindo senso crítico influindo na conscientização da existência da alteridade e, paralelamente, na inclusão do "outro" marginalizado e desumanizado, proporcionando condições de concretização do verdadeiro Estado Democrático de Direito no Brasil.

Para tanto, baseou-se na noção de alteridade e sua relação estrutural com a igualdade frente a efetivação do princípio da dignidade da pessoa humana em uma sociedade pluricultural e no papel do professor na infusão, a partir dos institutos e não pela letra seca da norma, de uma reflexão crítica, saindo a forma propedêutica e procedimentalista do ensino jurídico.

Observou-se a necessidade de o professor manter no ambiente de saber o estímulo ao senso crítico do homem, tornando progressivo o conhecimento de si mesmo e do "outro", fomentando o empoderamento, criando consciência, atitudes éticas, para a garantia dos direitos fundamentais, da inclusão e da legitimação do Estado Democrático de Direito.

\section{NOÇÃO DE ALTERIDADE E SUA ESTRUTURA RELACIONAL COM A DIFERENÇA}

Etimologicamente, o termo "alteridade" é abordado por diferentes vieses, seja pela psicologia, antropologia ou filosofia, sendo esta ultima o enfoque a ser adotado no desenvolvimento deste trabalho.

A psicologia suscita a ideia de "contrário a ego", ou seja, "o conceito que o indivíduo tem segundo o qual os outros seres são distintos dele ${ }^{1}$.

\footnotetext{
${ }^{1}$ LANNOY, Dorin. Dicionário Ilustrado de Psicologia, v.5. In Enciclopédia de psicologia Contemporânea. São Paulo: Itamaraty, 1973, p. 75.
} 
Para a antropologia o conceito de alteridade define a existência do indivíduo a partir da relação com o outro, isto é, "Nenhum indivíduo pode existir senão a partir da visão e do contato com o outro. Não pode haver indivíduo se não houver uma relação estabelecida entre ele e o outro ou outros (a coletividade) ${ }^{2}$.

A partir da expressão originária do latim alteritas (condição de ser outro, colocarse ou constituir-se como outro ${ }^{3}$ ), a filosofia desenvolve a noção de alteridade em reconhecer-se no outro, independentemente de eventuais diferenças, seja de ordem cultural, psíquica, física ou outra.

Da perspectiva da filosofia, a alteridade apresenta um conceito mais amplo que a diferença, todavia, mais restrito que a diversidade, pois de acordo com Aristóteles, esta última pode ser puramente numérica, enquanto que esta característica não se apresenta na alteridade, de outra banda à alteridade, diferentemente da diferença, aplica-se sempre a determinação da diversidade, assim

Aristóteles considerou que a distinção de um gênero em várias espécies e a diferença dessas espécies na unidade de um gênero implica uma Alteridade inerente ao próprio gênero: isto é, uma Alteridade que diferencia o gênero e o torna intrinsecamente diverso $(. . .)^{4}$.

Destarte, pode-se afirmar que alteridade é ser capaz de compreender o outro na completude da sua dignidade, na plenitude de seus direitos e, sobretudo, da sua diferença, po is os conflitos se propagam na medida em que as relações pessoais e sociais se apresentam desprovidas ou com menor provisão de alteridade. Partindo desta premissa a alteridade seria se colocar na posição do outro, encarar a vida, o Direito, colocando-se na posição do outro.

Considerando os acontecimentos históricos sob a perspectiva das guerras, do sofrimento, da dor e da morte, condições em que o outro é reduzido a nada, as reflexões conduzem a revalorização do sentido ético do ser humano e do respeito as diferenças ${ }^{5}$.

Em relação à diferença, Zygmunt Bauman ensina:

\footnotetext{
2 SIGNIFICADOS BR. O que é alteridade. Disponível em: https://www.significadosbr.com.br/alteridade. Acesso em 28.12.2015.

3 ABBAGNANO, Nicola. Dicionário de Filosofia, 3. ed. São Paulo: Martins Fontes, 1998, p. 34 e 35.

4 ARISTÓTELES, (Met. IV,9,1.018 112 e Met. V, 8, 1.058 a 4 ss), apud ABBAGNANO, Nicola. Dicionário de Filosofia. 3. ed. São Paulo: Martins Fontes, 1998, p. 34 e 35 . Disponível em: http://www.vcquervervcescuta.blogspot.com. Acesso em 29.12.2015.

5 GOMES, Carla Silene C. L. B. Lévinas e o outro: a ética da alteridade como fundamento da justiça. Dissertação (Mestrado). Pontifícia Universidade Católica do Rio de Janeiro, Rio de Janeiro, 2008, p. 14. Disponível <http://www.dominiopublico.gov.br/download/teste/arqs/cp113166.pdf> Acesso em: 04.01.2016.
} 
(...) que o descaso (...) é teorizado como reconhecimento do "pluralismo cultural": a política informada e defendida por essa teoria é o "multiculturalismo". Ostensivamente o multiculturalismo é orientado pelo postulado da tolerância liberal, pela preocupação com o direito das comunidades à auto-afirmação e com o reconhecimento público de suas identidades [...] seu efeito é uma transformação das desigualdades incapazes de obter aceitação pública em "diferenças culturais" coisa a ser louvada e obedecida ${ }^{6}$.

Nesse sentido Emmanuel Lévinas, aponta a importância de refletir sobre a necessidade de uma sociedade plural, fraterna e pacífica e alça o conceito de alteridade, a partir de uma concepção ético-filosófica, como princípio da relação humana ${ }^{7}$.

Para atingir tal intento, exige-se, "a garantia de participação igualitária dos grupos sociais minoritários e vulneráveis, $[\ldots]^{8 \%}$, proteção, deveras, especial, no âmbito da Justiça Constitucional.

Tem-se, assim, de antemão, que uma das imbricações entre minorias e grupos vulneráveis perpassa pelo viés da tolerância, sem a qual não se há falar em democracia, muito menos em cidadania, já que a intolerância subtrai dessa parcela da população o exercício de tais prerrogativas no seio social, levando-se a se expandir, na sociedade, o processo de formação de guetos, que representa, além de uma exclusão social, a negação da ideia de comunidade, tida como um lugar aconchegante e seguro. Tem-se, outrossim, que minorias e grupos vulneráveis não são expressões sinônimas, mas pelas circunstâncias de seus integrantes encontrarem-se nas mesmas situações fáticas de discriminação, intolerância e fragilidade, por parte de uma parcela dominante da sociedade, torna-se irrelevante a diferenciação conceitual e relevante, sim, a tutela que se pode oferecer a esses excluídos.

Pautado no inciso V do artigo $1^{\circ}$ da Constituição Federal de 1988 , pode se afirmar que o Brasil é um país especialmente pluralista, considerando até que o país possui diferenças e extremos nas manifestações da questão social. De tal forma que, gerar a igualdade sem distinção é o objetivo da República brasileira, é a inclusão dos excluídos, é tornar "visíveis" os marginalizados, tanto por parte do Estado, quanto por parte da sociedade.

Para que a dignidade humana seja alcançada na sua plenitude a Constituição $\underline{\text { Federal de } 1988 \text { apresenta em seu preâmbulo o principio da igualdade que }}$

\footnotetext{
6 BAUMAN, Zygmunt. Comunidade: a busca por segurança no mundo atual. Rio de Janeiro: Renovar, 2003, p.97-98.

7 HADDOCK-LOBO, Rafael. Da existência ao infinito: Ensaios sobre Emmanuel Lévinas. São Paulo: Loyola, 2006, p. 13.

8 SAMPAIO, José Adércio Leite. A Constituição e o Pluralismo na Encrusilhada (I) - A Justiça Constitucional como Guardiã das Minorias Políticas. In Revista Latino-Americana de Estudos Constitucionais, Belo Horizonte, Del Rey, n. 2, jun./dez. 2003, p. 94.
} 
(...) resplandece sobre quase todos os outros acolhidos como pilastras do edifício normativo fundamental alicerçado. É guia não apenas de regras, mas de quase todos os outros princípios que informam e conformam o modelo constitucional positivado, sendo guiado apenas por um, ao qual se dá a servir: o da dignidade da pessoa humana 9 .

Destarte, a Constituição Federal promulga a todos os brasileiros os mais diversos direitos, todos de caráter fundamental, mas é na dignidade humana que se encontra a epígrafe identificadora do reconhecimento da amplitude da pessoa e seu valor. Assim, assegurar a dignidade da pessoa humana requer o resguardo da igualdade material como forma de sobrepujar a discriminação e a intolerância o que se faz com base na própria Constituição brasileira que estabelece a discriminação positiva, sob a forma de tratamento preferencial para os grupos considerados discriminados, pois como bem esclarecer Joaquim B. Barbosa Gomes,

\begin{abstract}
A chamada discriminação positiva ou ação afirmativa consiste em dar tratamento preferencial a um grupo historicamente discriminado, de modo a inseri-lo [...], impedindo [...] que o princípio da igualdade formal, expresso em leis neutras que não levam em consideração os fatores de natureza cultural e histórica, funcione na prática como mecanismo perpetuador da desigualdade. Em suma, cuida-se de dar tratamento preferencial, favorável, àqueles que historicamente foram marginalizados, de sorte a colocá-los em um nível de competição similar ao daqueles que historicamente se beneficiaram da sua exclusão ${ }^{10}$.
\end{abstract}

A igualdade material passa a ser um mecanismo de promoção da igualdade a fim de combater as disparidades sociais, no sentido de tratar desigualmente os desiguais na medida da sua desigualdade, protegendo juridicamente partes da sociedade excluídas e vulneráveis no decorrer da história. Combater meramente à discriminação não é suficiente para o implemento desta igualdade. Nesse sentido, a concessão de tratamento mais favorável a parcelas da população em situação de desvantagem não caracteriza violação ao princípio da igualdade, pelo contrário, viabiliza a igualdade material, tendo em vista que a igualdade jurídica existe e se realiza no respeito à diferença.

Segundo Boaventura de Souza Santos ${ }^{11}$ as pessoas têm direito a serem iguais quando a diferença as descaracteriza, o que torna necessário uma igualdade que perfilhe as diferenças sem as reproduzir, mas que cumpra as necessidades humanas.

\footnotetext{
9 ROCHA, Carmem Lucia Antunes. Ação afirmativa: o conteúdo democrático do princípio da igualdade jurídica. In: Revista Trimestral de Direito Público. ${ }^{\circ} 15,1996$, p. 85.

10 GOMES, Joaquim B. Barbosa. Ação afirmativa \& Princípio Constitucional da Igualdade: o direito como instrumento de transformação social. A experiência dos EUA. Rio de Janeiro: Renovar, 2001, p. 22.

11 SANTOS, Boaventura de Souza. A Construção Multicultural da Igualdade e da Diferença. Rio de Janeiro: Civilização Brasileira, 2003 , in passim.
} 
O Estado deve ter por fim efetivar os direitos fundamentais materialmente constitucionais, para o desenvolvimento socioeconômico e assegurar a inclusão em cumprimento a dignidade da pessoa humana, fundamento da República Federativa do Brasil (artigo $1^{\circ}$, inciso III da Constituição Federal):

[...] é possível se pensar em modelos de organização do Estado nos quais o direito é instrumento de inclusão social, de modo a garantir participação substancial a todos, [...] a partir de um critério objetivo de justiça consubstanciado pela igualdade ${ }^{12}$.

O Estado opta entre duas posturas: neutralidade ou ativismo, isto é, ou aceita que o grupo majoritário subjugue o socialmente minoritário, ou instrumentaliza-se de ações inclusivas para combater desigualdades e, consequentemente, inibir violações aos direitos humanos e fomentar a inclusão social em uma sociedade plúrima.

\section{PLURALIDAde CULTURAL E O PRINCÍPIO DA DIGNIDADE DA PESSOA HUMANA}

A sociedade plural referenciada no tópico anterior difere de sociedade intercultural, sendo que esta tem intenção direta de fomentar o diálogo e a relação entre culturas e aquela “(...) a presença, numa mesma sociedade, de culturas diferenciadas e a existência de identidades nacionais, étnicas, religiosas ou rácicas distintas ${ }^{13}$ " de tal forma que ao se reconhecer diferente não se está reconhecendo desigual, apenas diferente. Diferentes e desiguais são coisas diferentes. A diferença é natural nos seres humanos, a desigualdade é artificial e precisa ser criada, porque ela torna a pessoa torna igual perante os seus iguais e desigual perante aqueles a que consideram desiguais e na escolha de um fator discriminatório uma diferença vira desigualdade.

\footnotetext{
12 BRITO ALVES, Fernando. Dos pressupostos das políticas públicas de inclusão. In: SIQUEIRA, Dirceu Pereira; ANSELMO, José Roberto (Orgs.). In Estudos sobre os direitos fundamentais e inclusão social: da falta de efetividade à necessária judicialização, um enfoque voltado à sociedade contemporânea. Birigui/SP: Boreal Editora, p. 133-46, 2010, p. 143.

13 INFOPÉDIA - In Língua Portuguesa com Acordo Ortográfico. Porto: Porto Editora, 2003-2016. Disponível em: http://www.infopedia.pt/\$sociedades-plurais. Acesso em: 04.01.2016.
} 
Sendo assim, carregado de conotações sobre o "eu e o outro", o discurso do respeito pelas diferenças culturais, traz sob a perspectiva da alteridade, que “(...) esse "eu e

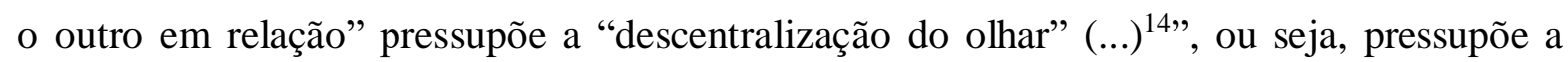
“(...) sensibilidade de se colocar no lugar do outro, de ver como o outro vê, aceitar um conhecimento que não se pauta exatamente nos nossos modelos de conhecimento $^{15}$.

Destarte, a noção de alteridade, “(...) supera o aceitar a existência do outro apenas como necessidade e interesse econômico, construindo-se assim uma identidade de aceitação do outro ${ }^{16 "}$ e é sob esta perspectiva que deve ser refletida a observância ou não do princípio da dignidade da pessoa humana.

Insta observar para os direitos humanos um tronco comum no referente a elementos de outras culturas, para que o multiculturalismo não impeça uma ética universal, devendo-se respeitar as diferenças culturais de cada sociedade, com seu respectivo sistema moral ${ }^{17}$. A dignidade da pessoa humana, representa, assim, "a consciência ética contemporânea compartilhada pelos Estados"18; o "ideal comum a ser atingido por todos os povos e todas as nações" ${ }^{19}$.

16 SOUZA, Maria Elena Viana. Pluralismo cultural e multiculturalismo na formação de professores: espaços para discussões étnicas de alteridade. In Revista HISTEDBR On Line. Campinas, n.19, set. 2005, p. 91. Disponível em: http://www.histedbr.fe.unicamp.br/revista/revis/revis19/art06_19.pdf. Acesso em 28.12.2015.

17 PIOVESAN, Flávia. Direitos humanos e o direito constitucional internacional. 5. ed. rev. e ampl., São Paulo: Max Limonad, 2002, p. 156-157.

18 PIOVESAN, Flávia. Direitos humanos e justiça internacional: um estudo comparativo dos sistemas regionais europeu, interamericano e africano. São Paulo: Saraiva, 2006, p. 13

19 MAZZUOLI, Valério de Oliveira (Org.). Coletânea de Direito Internacional, 2. ed. e ampl., São Paulo: RT, 2004, p. 419 
As minorias, multiculturalidade e grupos vulneráveis percorrem o caminho da tolerância, sem a qual não se ter e/ou viver uma democracia, quiçá uma cidadania, posto ser essa parcela da população excluída e podada em seus direitos. Estas minorias sofreram e sofrem processos de estigmatização, e por tal diferentes formas de desigualdades que resultam em uma exclusão social.

A sociedade multi ou pluricultural deve ter seus direitos fundamentais tutelados de maneira eficaz, mas para tanto, mesmo que brevemente, há de se definir o que vem a ser multiculturalismo que segundo Boaventura de Souza Santos ${ }^{20}$.

[...] designa originalmente, a coexistência de formas culturais ou de grupos caracterizados por culturas diferentes no seio de sociedades "modernas". Rapidamente, contundo, o termo se tornou um modo de descrever as diferenças culturais em um contexto transnacional e global.

E continua “[...] reconhece a pluralidade de culturas, definindo-as como totalidades complexas que se confundem com as sociedades, permitindo caracterizar modos de vida baseados em condições materiais e simbólica, [...]"21. Sendo que o autor divide o significado de multiculturalismo em 03 (três) princípios

1. a existência de uma multiplicidade de culturas no mundo;

2. a co-existência [sic] de culturas diversas de um mesmo Estado-nação;

3. a existência de culturas que se interinfluenciam tanto dentro como além do Estado-nação.

\footnotetext{
${ }^{20}$ SANTOS, Boaventura de Souza; NUNES, João Arriscado. Introdução: para ampliar o cânone do reconhecimento, da diferença e da igualdade. In: SANTOS, Boaventura de Souza (Org.). In: Reconhecer para libertar: os caminhos do cosmopolitismo multicultural. Rio de Janeiro-RJ: Civilização Brasileira, 2003, p. 26.
} 
${ }^{21}$ SANTOS, Boaventura de Souza; NUNES, João Arriscado. Introdução: para ampliar o cânone do reconhecimento, da diferença e da igualdade. In: SANTOS, Boaventura de Souza (Org.). In: Reconhecer para libertar: os caminhos do cosmopolitismo multicultural. Rio de Janeiro-RJ: Civilização Brasileira, 2003, p. 27.

Desse modo, observa-se que multiculturalismo pode cooptar tanto conteúdo emancipatórios quanto contra. E pode mesmo ser instrumento para regular comportamentos e práticas em Estados-nação ou globalmente. Aqui é visto como um projeto emancipatório, pois este se funda nas diferenças e no direito a essas diferenças na construção da vida em sociedade.

O Brasil é um país multicultural, quer pela sua dimensão quer pela sua própria forma de desenvolvimento, o que se vê é uma existência de culturas ou tradições múltiplas, e não há como conciliar tais diferenças sem o direito, sem os Direitos Fundamentais de uma vida digna, sendo que esses direitos fundamentais que devem operar nessa sociedade plúrima e multicultural.

Sob o ângulo do Direito o multiculturalismo é a diversidade, a alteridade, e a função desse direito é regular uma a convivência pacífica entre essas diversas culturas, da mesma forma que o pluralismo jurídico é reconhecido no preambulo do Texto Constitucional. A função do Direito não se fixaria apenas em criar regras/normas, mas também em tornar acessível a ordem jurídica no acolhimento das individualidades, onde deve ser entendido como um componente cultural e social, tornando aquelas pessoas que seriam suas destinatárias também suas fontes de concepção e interpretação.

\section{ALTERIDADE E O PAPEL "SOLIDÁRIO" DO PROFESSOR}

No campo do ensino, em sala de aula, espera-se que um professor que, academicamente, se formou para tanto, entenda o Direito como um fenômeno de formação e efeitos, de forma a trabalhar o ensino do Direito a partir dos conceitos gerais, não dos específicos. Em sala de aula, o professor deve ter uma matriz mais aberta, além de ser preparado e ter a intenção de informar o instituto a partir dos institutos e não "norma por norma", a fim de ensinar o aluno a refletir.

A formação apenas propedêutica, procedimentalista, pode levar ao isolamento do ensino jurídico sendo que de outro lado, a formação, simplesmente dogmática, pode ensejar no risco da criação de burocratas do Estado, de manutenção do status quo. A partir deste ponto de vista o conhecimento transmitido no formato "quem ensina/quem aprende", condicionaria os alunos a compreender o Direito como um conjunto de 
valores que condiciona a sociedade, o que produz uma capacidade crítica muito pequena, inibindo as possibilidades do "aprender a pensar", cunhada na formação muito mais que tem muito de procedimental que facilita a construção de linhas mentais, práticas e Inter comunicacionais que constituem o cerne, a alma do fenômeno jurídico.

Assim dar-se-ia a formação de um sujeito atento à realidade, atento as várias possibilidades que a humanidade por tanto tempo instituiu como Direito. No próprio processo de conhecimento, não é possível usar motes retóricos para resolver todos os problemas, ainda que se considere a dignidade humana como o vetor máximo do ordenamento.

A atual Constituição Federal de 1988 em seu preâmbulo apresenta seus motivos: instituir um Estado Democrático, com o fim de assegurar o exercício dos direitos sociais e individuais, a dignidade, a liberdade, bem-estar, a igualdade e a justiça como valores supremos da sociedade fraterna, pluralista e sem preconceitos que almeja (Art. $5 \%$ CF), embora estas garantias ainda estejam longe de serem efetivadas plenamente.

Assim, para tal deve-se realizar uma repartição de poder social alcançando-se a regra básica da justiça social que é afiançar o acesso a tais poderes e funções. Mas o acesso a essa justiça perpassa por conflitos entre aqueles que nada tem, colocados à margem, e os que tem, ou seja, conflitos de desigualdades.

A Constituição de 1988 reconhece uma só cidadania, mas não há controle eficaz da discriminação, nem busca efetiva de distribuição de renda, não se podendo olvidar da corrupção que devasta o país. Portanto, pode-se falar que não há democracia, pois quando esta existe o poder do Estado é melhor delimitado garantindo-se os direitos fundamentais dos cidadãos, transformando o Estado em seu instrumento.

Miguel Reale ${ }^{22}$ ensina que o conhecimento científico sugere uma tipologia, uma divisão em hierarquias da qual não pode prescindir, mas apropriadas a cada realidade. Sendo que para o direito como ciência funciona da mesma forma, pois sempre á uma categorização de condutas nos moldes das experiências humanas.

Observa-se que a construção do direito é um processo que se desenvolve dia a dia, e sob esta perspectiva é que busca se analisar o papel do professor capaz de incutir nos alunos compreensão crítica, pautada nos valores dos direitos fundamentais, donde se retiram os valores éticos.

\footnotetext{
22 REALE, Miguel. Graduação do conhecimento - o conhecimento vulgar e científico. In: Filosofia do Direito. 19. ed. São Paulo: Saraiva, 2002. Cap. 5, p. 53-64.
} 
Como fenômeno dialético o direito não é ato, não tolera desobediências. $O$ Direito não está na lei nem na Constituição, que também é um texto normativo e resultado de negociação política de diversas forças em determinado momento da sociedade.

O Direito é um fenômeno dialético porque sem dúvida evolui, e a ele podem ser aplicadas algumas leis: unidade e luta dos contrários. A negação da negação. A interrelação dos fenômenos, pois não se constrói o Direito sem unidade e luta dos contrários, é preciso, portanto, que haja contrariedade, assim como para a formação critica do aluno essa necessidade é crucial.

Assim se explica o estudo da filosofia para entender a maneira como o ser humano se relaciona com a sua realidade. E essa relação entre ser humano e realidade implica que o ser humano assuma um certo jeito de conhecer essa realidade. Esse jeito de conhecer implica fugir do bom senso. O grande inimigo do pensar filosófico é um bom senso. Alguns colocam de maneira mais enfática e menos rude: o senso comum. Dizer que se pensará filosoficamente implica decodificar o que se pode chamar de "bom ou mau senso", implica fugir do senso comum. O pensar filosófico não pode se dar ao luxo de criar uma relação entre ser humano e realidade a partir do senso comum. O que importa ao pensar filosófico é a conquista do episteme, ou seja, chegar às primeiras causas do conhecimento. Esse raciocínio, do ponto de vista filosófico, pressupõe uma compreensão do mundo.

No campo da experiência jurídico-cultural a ideia é aprender experiências jurídicoculturais, que requer a admissão que nenhuma experiência jurídico-cultural é exatamente igual à outra e não podemos traduzir essas experiências jurídico-culturais como meros convencionalismos de maneira universal. Ou seja, no mundo social e da experiência jurídico- cultural a soma dos quadrados dos catetos nunca será o quadrado da hipotenusa, ou seja, nunca se poderão usar as técnicas das ciências exatas ou da biologia para o campo da experiência cultural.

Na trilha de Anísio Teixeira é de se entender que a melhora da educação brasileira se encontra ligada à formação dos profissionais da área em todos os níveis, evitandose o autodidatismo, o retraimento, a estrutura obsoleta e sem investimentos das instituições universitárias, bem como a postura arcaica de seus professores. Desse modo em que as universidades brasileiras se encontram, não há como ignorar a discriminação da educação e do saber, atuando somente na reprodução do conhecimento. 
Em verdade, cabe às universidades nacionais implementar a socialização do conhecimento, do saber, além de preparar o aluno, futuro profissional, para operar em sociedade e em prol desta. Para Anísio Teixeira o encargo da universidade seria:

Uma função única e exclusiva. Não é só difundir conhecimento. O livro o faz. Não é conservar a experiência humana. O livro também conserva. Não é preparar práticas profissionais, ou ofícios de arte. A aprendizagem direta os prepara, ou, em último caso, escolas muito mais singelas que a universidade.

[...] formular intelectualmente a experiência humana, sempre renovada, para que a mesma se torne consciente e progressiva ${ }^{23}$.

Como concebe Anísio Teixeira as universidades brasileiras deveriam priorizar e permitir que a cultura nacional fosse transmitida:

\begin{abstract}
As escolas superiores brasileiras, não obstantes serem profissionais, cumpriam, de algum modo, herdadas do passado, as funções de educar o homem para a cultura geral e desinteressada. Assim sendo, a sua elite formava-se em escolas superiores que, embora visando à cultura profissional, davam, sobretudo ênfase ao sentido liberal das antigas e nobres profissões do Direito e Medicina. [...] importava o fato de transmitir uma cultura dominantemente européia. De modo que tínhamos duas alienações no ensino superior. A primeira grande alienação é que o ensino, voltado para o passado e sôbre o passado, nos levava ao desdém pelo presente. A segunda alienação é que tôda a cultura transmitida era cultura européia. Recebíamos ou a cultura do passado, ou a cultura européia. [...] estávamos muito mais inseridos na verdadeira cultura ocidental e até na antiga - latina e grega - do que em nossa própria cultura. ${ }^{24}$
\end{abstract}

Assim, para a efetiva atuação das universidades brasileiras se faz necessária ações consolidadas, que ultrapassem àquelas funções já consideradas. Necessita-se que os profissionais das instituições universitárias entendam e transmitam os problemas nacionais, ao mesmo tempo em que aprofundem seus estudos e trabalhem na busca de soluções.

Ana Waleska Pollo Campos Mendonça explica que, nos moldes de Anísio Teixeira, o modelo de universidade consistia em uma:

[...] instituição, por excelência, onde se construiria a cultura expressiva das sociedades contemporâneas, de base científica e tecnológica, e onde se formaria o novo intelectual a quem competiria exercer a direção da sociedade. [...] para se conseguir a relativa homogeneidade que viabilizaria o próprio exercício da direção social. ${ }^{25}$

\footnotetext{
23 TEIXEIRA, Anísio Spínola. Educação e universidade. Rio de Janeiro: UFRJ, 1988, p. 17-18.

24 TEIXEIRA, Anísio Spínola. Uma perspectiva da educação superior no Brasil. Revista Brasileira de Estudos Pedagógicos. Rio de Janeiro, v.50, n. 111, jun./ set. 1968, p. 27-8.

25 MENDONÇA, Ana Waleska Pollo Campos. Universidade, ciência e cultura no pensamento de Anísio Teixeira. In: Revista de comunicação, cultura e política. ALCEU, v.4, n.7, jul./dez. 2003. Disponível em: http://publique.rdc.puc-rio.br/revistaalceu/media/alceun7-Mendonca. pdf. Acesso em: 12 fev. 2016, p. 153-4
} 
Ainda hodiernamente se observa que falta consolidar um ensino universitário que seja um instrumento de transformação da sociedade. Carecem de estruturas, pesquisa, projetos que reestruturem o saber, o aluno e, consequentemente, a sociedade.

\section{O PAPEL DO PROFESSOR É INFUNDIR "MEDO" COLOCANDO-SE NA POSIÇÃO DE QUALQUER UM?}

Primeiramente, não se pode olvidar que a educação é assentada como bem público, de caráter próprio e cidadã, sendo que por aludir a cidadania deve ser em si consciente no seu exercício e por qualificar para o labor profissional, bem como gratuita e obrigatória é dever do Estado, tendo ocorrido diversas reformas educacionais que atuaram não apenas no nível da escola, mas sim no sistema como um todo. Hodiernamente questões de desvalorização e desqualificação da força do trabalho docente indicam que essas reformas repercutem em uma desprofissionalização e proletarização da docência.

Tais reformas educacionais buscam uma transformação fértil com igualdade e, para tanto, pregam a transformação da composição, estrutura e aspectos organizacionais das redes de ensino, a fim de implementar percepção de produtividade, excelência, eficiência e eficácia, pois na postura atual tem se avaliado que a educação é o principal mecanismo de distribuição de renda e locomobilidade social, posto que dirigida à formação para o trabalho e a educação orientada para a gestão ou disciplina da pobreza ${ }^{26}$.

Procura-se uma organização sistêmica devido ao dever de universalidade, por isso essas apresentam características de padronização e massificação dos processos pedagógicos, bem como dos administrativos.

Contudo, entende-se não existir mais espaço para aquela educação tradicional, ficada na transmissão simples do saber, no autoritarismo e verticalizada/burocrática. A educação deve-se fundar na democracia, no trabalho coletivo, ser participativa e de qualidade.

Entretanto, o que se tem observado, em realidade, é uma mercantilização da educação superior, que em decorrência da globalização se transformou em objeto de interesse

26 OLIVEIRA, Dalila Andrade. Educação básica: gestão do trabalho e da pobreza. Petrópolis: Vozes, 2000, in passim. 
do capital. $^{27}$ Sendo que tal mercadorização ocorre também face ao aumento da demanda, resultante do crescimento do ensino médio e fundamental.

Combinados tais elementos tem-se a criação de um mercado próspero que, de acordo com dados da revista Exame de 22 de dezembro de 2008, avaliava-se movimentar $\mathrm{R} \$ 90$ bilhões por ano, o equivalia a quase 3\% do PIB, embora não suplantasse os gastos públicos em educação, considerando-se a oferta de cursos - presenciais e a distância - bem como à produção de materiais como livros, apostilas e softwares.

Lembrando que Tom Bottomore define mercadoria como tudo que possa ser "comprado ou vendido" numa perspectiva de acumulação de capital ${ }^{28}$, observa-se que a educação se transformou em mercadoria, e uma mercadoria importante, muito embora o texto constitucional brasileiro afirme ser a educação um direito social e um dever do Estado que deve buscar diferenciação institucional e diversificação de fontes de manutenção da educação, pesquisa e ética.

Contudo, o Decreto $\mathrm{n}^{\mathrm{o}}$ 2.306, de 19 de agosto de 1997, perfilhava a educação superior como bem comercializável, o artigo $7^{\circ}$ de referido Decreto estabelece que:

As instituições privadas de ensino classificadas como particulares, em sentido estrito, com finalidade lucrativa, ainda que de natureza civil, quando mantidas e administradas por pessoa física, ficam submetidas ao regime de legislação mercantil, quanto aos encargos fiscais, parafiscais e trabalhistas, como se comerciais fossem, equiparados seus mantenedores e administradores ao comerciante em nome individual ${ }^{29}$.

Embora, posteriormente, os Decretos $\mathrm{n}^{\mathrm{o}} \mathrm{s} 3.860 / 2001$ e 5.773/2006 tenham revogado aludido Decreto $\mathrm{n}^{\circ}$ 2.306/97, o teor de retro citado artigo mantem-se válido.

Impedir a mercantilização da educação, seja por meios legais formais, seja por meios político-sociais, não se traduz eficaz. Não há mais como proibir a circulação de tal mercadoria face, inclusive, a presente demanda.

Entende-se que a educação deve ser dirigida em combater a incompreensão estrutural da ética, no sentido de incentivar o senso crítico e o professor tem esse privilégio de incitar a busca por respostas guerreando contra a resistência de se ter senso crítico, ir contra o mundo mediático por sua autoridade doutrinal, moral e intelectual.

\footnotetext{
27 OLIVEIRA, Romualdo Portela de. A transformação da educação em mercadoria no Brasil. Disponível em: http://www.scielo.br/pdf/es/v30n108/a0630108.pdf. Acesso em: 18 fev. 2016.

28 BOTTOMORE, Tom. Dicionário do pensamento marxista. Rio de Janeiro: Zahar, 1998, p. 266.

29 BRASIL. Decreto no 2.306, de 19 de agosto de 1997 - Regulamenta, para o Sistema Federal de Ensino. Disponível em: http://www.planalto.gov.br/ccivil_03/decreto/D2306impressao.htm. Acesso em: 16 fev. 2016
} 
Se colocar na posição de "qualquer um" é justamente se colocar na posição oposta que remete a ideia "dos outros", é se inserir no contexto, seja ele político ou social. Quando se está inserido no contexto sob estas perspectivas, a visão a que temos nos possibilita compreender as questões que nos rodeia, a força que dela emana em relação a questão posta é o efeito estabilizador que a posição "dos outros" não produz.

Colocar-se no papel do outro é não se ater a noções preconcebidas ou aquilo que a sociedade coloca como posto e definido. Colocar-se no lugar de qualquer um é enxergar os acontecimentos sob diversos olhares, sem estar preso a um controle social. O professor é convidado a entrar em sena, assumir o lugar de algum (qualquer) personagem oprimido, espera-se que aqueles sensibilizados que entram, possam se colocar na posição de qualquer um deles, mesmo que não vivam aquela situação.

O poder se vale da posição "dos outros" que fragiliza e infundi o "medo", sentimento que sob a perspectiva política fortalece o sistema. O poder a que aqui se refere é no sentido de classe dominante, detentora do controle social em relação ao outro e infundir o medo no outro não como professor, mas sim inspirar o desejo de análise crítica dos fatos para exigir mudanças da classe governante, do sistema, sendo que tal, sim, seria o fator de geração de medo no status quo.

Quando colocado na posição de "qualquer um" e infundindo medo nos termos supramencionado formando, portanto, pessoas críticas, a desestabilização do sistema é latente e o medo" providencial e ajustador.

No que concerne a análise desse ponto de vista crucial ser posto para o professor no desenvolvimento do seu papel de infundir ou não o medo, vale ressaltar que, a figura em tela, carrega em si o poder que pode ser o de infundir o "medo" naqueles estudantes, usando seu poder apenas como um repetidor/transmissor de conhecimentos vazios de análise crítica ao contrário de dispor de um poder de reflexão, de formação de opinião crítica, todavia sua atuação nesse sentido só é possível quando se coloca na posição de "qualquer um" e assim consegue alcance para enunciar proposições que podem implicar "qualquer um". Esse movimento e seus efeitos sim causam o verdadeiro "medo" e com isso a tarefa a que se propõe ou deveria se propor o professor, se efetiva.

Deve-se manter um ambiente de saber para se aparelhar o homem a cultivar o saber vivo, renovar a experiência humana, tornando-a progressiva, crítica e conscientes. Sem que se cumpra as funções da universidade o povo brasileiro, a Nação não terá "existência autônoma, vivendo, tão somente, como um reflexo dos demais" 30 . 


\section{CONSIDERAÇÕES FINAIS}

Abordada sob o enfoque filosófico a alteridade busca compreender o outro na completude de sua dignidade e de seus direitos e sobretudo na diferença, possibilitando ao individuo se que se ao se colocar no lugar do outro, seja capaz de refletir e respeitar as diferenças.

Em um país pluralista como o Brasil as diferenças e extremos desajustes sociais são latentes e se espelham em situações fáticas de discriminação, intolerância e fragilidade social, sendo de extraordinária relevância a observância da dignidade humana sob a perspectiva da aplicação da igualdade material para inclusão dos excluídos.

A pluralidade cultural composta de diferentes etnias, religiões dentre outras diversidades são diferenças naturais dos seres humanos, no entanto forma uma sociedade carregada de conotações sobre o "eu" e o "outro", cujo discurso urge pela incidência da alteridade, pela descentralização do olhar, pela observância da intangibilidade da dignidade humana e pela sensibilidade de aceitação de conhecimento que não se apresentam nos mesmos parâmetros para todos. Tem-se, aqui, que a alteridade e o respeito ao direito do outro assumindo a função de regular uma convivência pacífica neste mundo pluricultural.

Sobretudo, o papel da alteridade na figura do professor apresenta sua relevância mais acentuada da perspectiva da formação do individuo capaz de refletir e impingir no outro a consciência e o senso crítico capaz de tornar a convivência social pluricultural pacifica e as diversidades, diferenças naturais dos seres humanos. Mas não apenas isso, a papel deste professor vai além, forma cidadãos atentos a realidade, apto e seguro a buscar a garantia dos seus direitos, dotado de bom senso e de conhecimento que o possibilita a romper com as amarras do controle social, da dominação da classe governante.

30 TEIXEIRA, Anísio Spínola. Educação e universidade. Rio de Janeiro: UFRJ, 1998, p. 34 
Este cidadão moldado em sala de aula pela infusão do "medo" do ponto de vista da formação crítica, consciente e aberta para as diversidades e superação dos obstáculos, controle social, político e econômico é o resultado efetivo do papel do professor, pois apenas ensinar a absorver dados não é transmitir conhecimento. Transmitir conhecimento é dar empoderamento, é ser criador de consciência, é estimular atitudes éticas e de senso crítico. O professor deve ser operador de transformações, pedra fundamental onde uma sociedade deve ser construída. Ser professor é ser capaz e se empenhar em formar bons cidadãos.

\section{REFERÊNCIA IBLIOGRÁFICAS}

ABBAGNANO, Nicola. Dicionário de Filosofia. 3. ed. São Paulo: Martins Fontes, 1998.

ARISTÓTELES, (Met. IV,9,1.018 112 e Met. V, 8, 1.058 a 4 ss), apud ABBAGNANO, Nicola. Dicionário de Filosofia. 3. ed. São Paulo: Martins Fontes, 1998, p. 34 e 35. Disponível em: http://www.vcquervervcescuta.blogspot.com. Acesso em 29.12.2015.

BAUMAN, Zygmunt. Comunidade: a busca por segurança no mundo atual. Rio de Janeiro: Renovar, 2003.

BRASIL. Decreto n 2.306 , de 19 de agosto de 1997 - Regulamenta, para o Sistema Federal de Ensino. Disponível em: http://www.planalto.gov.br/ccivil_03/decreto/D2306impressao.htm. Acesso em: 16 fev. 2016.

BOTTOMORE, Tom. Dicionário do pensamento marxista. Rio de Janeiro: Zahar, 1998.

BRITO ALVES, Fernando. Dos pressupostos das políticas públicas de inclusão. In: SIQUEIRA, Dirceu Pereira; ANSELMO, José Roberto (Orgs.). In Estudos sobre os direitos fundamentais e inclusão social: da falta de efetividade à necessária judicialização, um enfoque voltado à sociedade contemporânea. Birigui/SP: Boreal Editora, 2010.

GOMES, Carla Silene C. L. B. Lévinas e o outro: a ética da alteridade como fundamento da justiça. Dissertação (Mestrado). Pontifícia Universidade Católica do Rio de Janeiro, Rio de Janeiro, $2008 . \quad$ Disponível http://www.dominiopublico.gov.br/download/teste/arqs/cp113166.pdf Acesso em: 04.01.2016.

GOMES, Joaquim B. Barbosa. Ação afirmativa \& Princípio Constitucional da Igualdade: o direito como instrumento de transformação social. A experiência dos EUA. Rio de Janeiro: Renovar, 2001.

GUSMÃO, Neuza Ma Mendes de. Antropologia e Educação: Origens de um diálogo. In: 
Antropologia e Educação. Interface do ensino e da pesquisa. Caderno Cedes, 43, 1997.

HABERMAS, Jurgen. A inclusão do outro: estudos de teoria politica. Trad. George SPERBER e Paulo Astor Soethe (UFPr.). São Paulo: Edições Loyola, 1997.

HADDOCK-LOBO, Rafael. Da existência ao infinito: Ensaios sobre Emmanuel Lévinas. São Paulo: Loyola, 2006.

INFOPÉDIA - In Língua Portuguesa com Acordo Ortográfico. Porto: Porto Editora, 20032016. Disponível em: http://www.infopedia.pt/\$sociedades-plurais. Acesso em: 04.01.2016.

LANNOY, Dorin. Dicionário Ilustrado de Psicologia, v.5. In Enciclopédia de psicologia Contemporânea. São Paulo: Itamaraty, 1973.

MAZZUOLI, Valério de Oliveira (Org.). Coletânea de Direito Internacional, 2. ed. e ampl., São Paulo: RT, 2004.

MENDONÇA, Ana Waleska Pollo Campos. Universidade, ciência e cultura no pensamento de Anísio Teixeira. In: Revista de comunicação, cultura e política. ALCEU, v.4, n.7, jul./dez. 2003. Disponível em: http://publique.rdc.puc-rio.br/revistaalceu/media/alceun7- Mendonca. pdf. Acesso em: 12 fev. 2016.

OLIVEIRA, Romualdo Portela de. A transformação da educação em mercadoria no Brasil. Disponível em: http://www.scielo.br/pdf/es/v30n108/a0630108.pdf. Acesso em: 18 fev. 2016.

OLIVEIRA, Dalila Andrade. Educação básica: gestão do trabalho e da pobreza. Petrópolis: Vozes, 2000.

PIOVESAN, Flávia. Direitos humanos e o direito constitucional internacional, 5. ed. rev. e ampl., São Paulo: Max Limonad, 2002.

ROCHA, Carmem Lucia Antunes. Ação afirmativa: o conteúdo democrático do princípio da igualdade jurídica. In: Revista Trimestral de Direito Público. nº 15, 1996.

SAMPAIO, José Adércio Leite. A Constituição e o Pluralismo na Encrusilhada (I) - A Justiça Constitucional como Guardiã das Minorias Políticas. Revista Latino-Americana de Estudos Constitucionais, Belo Horizonte, Del Rey, n. 2, jun./dez. 2003.

SANTOS, Boaventura de Souza. A Construção Multicultural da Igualdade e da Diferença. Rio de Janeiro: Civilização Brasileira, 2003.

SIGNIFICADOS BR. O que é alteridade. Disponível em: https://www.significadosbr.com.br/alteridade. Acesso em 28.12.2015.

SOUZA, Maria Elena Viana. Pluralismo cultural e multiculturalismo na formação de professores: espaços para discussões étnicas de alteridade. In Revista HISTEDBR On Line. Campinas, n.19, 2005.2 Disponível em: 
http://www.histedbr.fe.unicamp.br/revista/revis/revis19/art06_19.pdf. Acesso em 28.12.2015.

TEIXEIRA, Anísio Spínola. Educação e universidade. Rio de Janeiro: UFRJ, 1988.

Uma perspectiva da educação superior no Brasil. Revista Brasileira de Estudos Pedagógicos. Rio de Janeiro, v.50, n. 111, jun./ set. 1968. p. 21-82. 